\title{
A Study of the Relationships Among Total Quality Management, Executive Ability, and Sustainable Competitive Advantage
}

\author{
Rui Chen \\ Huaiyin Institute of Technology, Huai'an, China \\ Chin-Lai Su, Cheng-Hua Wang, Yuan-Duen Lee \\ Chang Jung Christian University, Taiwan
}

\begin{abstract}
It is very important for organization to deal with and balance the challenge of environmental complexity and inner resources scarcity. This study considers total quality management (TQM) as a factor linking internal and external of organization and executive ability as linkage to promote and coordinate internal-external elements and then organization obtains its sustainable competitive advantage. The research surveyed effective samples 252 and used Structural Equation Model (SEM) and discriminated analysis for analysis and testing. The results indicate that TQM positively affects executive ability and firm sustainable competitive advantage. Executive ability affects firm sustainable competitive advantage and has the mediating effect between TQM and firm sustainable competitive advantage. Managerial practice implications, limitations, and future research directions have been discussed.
\end{abstract}

Keywords: total quality management (TQM), executive ability (EA), sustainable competitive advantage (SCA), Structural Equation Model (SEM)

\section{Introduction}

Total quality management (TQM) is a widespread managerial philosophy, and TQM system uses the IPO (Input-Process-Output) conceptual model to show the relationship between the factors in a TQM system and the participants (Wang, Chen, \& Chen, 2012). TQM-linked practice helps to enhance an organization's sustainable competitive advantage by enhancing its managerial competencies. TQM focuses on continuous process improvement, and the real contributors to the successful implementation require support from the highest levels of management (Doeleman, ten Have, \& Ahaus, 2012).

According to the complex resource-based view (C-RBV theory), external environmental factors and internal resources, together constitute the two aspects of an organization's sustainable competitive advantage. The complexity of external environment provides opportunities and threats, and internal resources provide the

Rui Chen, associate professor, Business College, Huaiyin Institute of Technology, Huai'an, China.

Chin-Lai Su, Ph.D. student, Graduate School of Business and Operations Management, Chang Jung Christian University, Taiwan.

Cheng-Hua Wang, professor, Graduate School of Business and Operations Management, Chang Jung Christian University, Taiwan.

Yuan-Duen Lee, professor, Graduate School of Business and Operations Management, Chang Jung Christian University, Taiwan.

Correspondence concerning this article should be addressed to Rui Chen, 89, BeiJing Roda, Huai'an City, JiangSu Province, China. 
foundation for timely responses to these. The match between these two ultimately determines the competitiveness of the organization and its sustainability. C-RBV links the external and internal elements of organization and focuses on the complex processes that build system-level resources over time. Management actions based on this complexity can influence the organizational system and help it to build and leverage strategic resources (Dóci \& Hofmans, 2015).

However, concept does not automatically become a reality. A brilliant strategy may put you on the competitive map. But only solid execution keeps you there (Neilson, Martin, \& Powers, 2008). The view in this paper considers that the appropriate application and practice of strategic resources of TQM can bring real sustainable competitive advantage and execution is at the heart of successful TQM implementation, especially, top management needs transformational leadership skills. All organization members including leadership and followers play the great role in TQM-oriented activities and lead to scientific and reasonable reality of the enterprise's sustainable superior performance.

The purpose of this study is to examine three issues: (1) determining the relationships among total quality management (TQM), executive ability (EA), and sustainable competitive advantage (SCA), (2) examining if executive ability fosters sustainable competitive advantage and mediates the TQM and sustainable competitive advantage, and (3) testing a proposed model to give a clear explanation of the relationships among TQM, EA, and SCA.

\section{Literature Review}

\section{C-RBV Theory and TQM Factors}

The C-RBV was first put forward by Colbert, Kurucz, and Wheeler in 2004. Based on this theory, managing sustainability depends critically on building internal capacity and strategic resources with respect to managing organizational connectivity, commitment, culture, and capabilities. The internal paradox of the RBV rests in the contention that in order to shield resources from scrutiny and imitation by competitors, and thereby protect a sustain competitive advantage, the nature and composition of the resource must remain causally ambiguous, to the degree that its origins may remain a mystery - even to the firm possessing it. This logical conundrum was resolved by the extension of the RBV by employing concepts from the science of complexity, and thus combining living systems principles and the concept of the sustainable organization (Colbert et al., 2005).

The factors of TQM can be subdivided into two groups. One group are external factors (soft aspects), such as internal/external cooperation, customer focus, employee fulfillment, and learning. The other aspect refers to the internal elements of the design, implementation, and improvement of a managerial system (technical factors or hard aspects), such as process management and continuous improvement.

A large number of recent studies focus on the critical dimensions of the TQM and their impacts on organizational performance. But the conclusions of these works remain paradoxical and in conflict, and most are static studies, which also limits their reliability. In this sense, C-RBV theoretical model supports dynamic research into TQM, and covers both the related internal and external factors.

\section{The Relationship Between Total Quality Management and Sustainable Competitive Advantage}

Total quality management (TQM). The idea of total quality management (TQM) grew out of the early 1980's in the USA (Khanam, Siddiqui, \& Talib, 2013). According to its creator, Deming, TQM is a 
management philosophy that makes use of a particular set of principles, practices, and techniques to expand business and profits that provides a change to enhance productivity by avoiding rework, rejects, waste, customer complaints, and high costs.

Meaning of TQM has been constantly enriched and developed. TQM is composed of three terms of total, quality, and management, and is the art of managing the whole company to achieve the excellence, also defined as an organization-wide philosophy requiring all employees at every level to focus their efforts to help improve each business activity of the organization. Some scholars give definitions of TQM from the perspective of mechanisms and outcomes. For example, Wiele et al. (2000) and Talib et al. (2011) defined TQM as the fulfillment of customer needs and the continuous improvements in quality, making it the responsibility of every employee.

In general, TQM is a way to enhance the traditional way of doing business. It can be a managerial philosophy (Sureshchandar et al., 2001), an organizational perception and culture, a technique and working mechanism, and also a process, practice (Kanji \& Wallace, 2000) and outcome.

Sustainable competitive advantage (SCA). Competitive advantage is built in the logic of value creation and distribution (Wade \& Hulland, 2004). Sustainability has traditionally been defined as a condition in which a "firm's competitive advantage resists erosion by competitor behavior". RBV (Barney, 1991) originally introduced the notion of inability to replicate to this context, saying that competitive advantage is sustained only if it continues to exist after efforts to duplicate that advantage have ceased. Ten Have et al. (2003) examined why large, complex organizations were capable of excellence over the long-term, and formulated four guiding concepts as the basis for a distinctive approach to organizing a firm (Doelemana et al., 2012).

These earlier studies show that competitive advantage is the ability to stay ahead of present or potential competition. They also appear that the resources held by a firm and the business strategy it adopts will have a profound impact on the ability to obtain and sustain a competitive advantage (Sureshchandar et al., 2001). TQM focuses on continuous process improvement (Wang et al., 2012) and is a proven technique to guarantee survival competitive markets. The creation of knowledge through TQM-linked activities helps the deployment of distinctive competencies at the heart of the organization. Therefore, this study suggests that TQM has a positive effect on a firm's sustainable competitive advantage, and thus the following hypothesis is proposed.

Hypothesis 1 (H1): Total quality management (TQM) positively impacts on sustainable competitive advantage (SCA).

\section{Executive Ability (EA)}

A brilliant strategy may put you on the competitive map. But only solid execution keeps you there (Neilson, Martin, \& Powers, 2008). Based on thousands of assessments of their organization's capabilities, the author found that lots of employees considered their companies are not very good at quickly translating "important strategic and operational decisions into action". They focused on "the fundamentals of good execution", and put forward their standpoint of excellent execution path of "clarifying decision rights and making sure information flows where it needs to go".

Richardson proposed an "Integrative Framework for Strategy Execution". His proposed Business Model included three main parts: the value proposition, the value creation and delivery system, and value capture.

Chatterjee, Narayanan, and Malek (2016) presented a COAR (Customers' and stakeholders' outcomes, Objectives, Activities, Resources that collectively form the execution capabilities) map to develop execution 
imperatives. The authors considered executive ability as a set of interlinked activities that convert business strategy into effective operations and a COAR map is built around a set of internal activities that are the keys for delivering customer values profitably.

From above review it is found that the executive ability involves many aspects of authority, communication, information flow, value creation and delivery and activities, etc. This research considers human resources as the first factors of executive ability and focuses on how to stimulate human's enthusiasm, positivity, and dynamic role.

Early literature studies indicated that the relationship between total quality management and leadership/employee is a mutually effective relationship. Waldman's research (1993) manifested that transformational leadership can be logically connected to TQM-oriented behavior. TQM activities stimulate the emergence of transformational leadership, employee fulfillment and learning.

Anupam Das who made an analysis of three applications of total quality management (TQM) in the government sector demonstrates the importance of leadership/employee. Its conclusion appears; the Oregon Judicial Department's TQM project was judged a marginal success due to the court's failure to recognize that TQM is a management philosophy requiring leadership, commitment, and a central purpose. In contrast, Florida's Fourth District Court of Appeals provided results that demonstrate TQM success when leaders are fully committed and communicate a clear purpose to the employees (Kluse, 2009).

In organizational level, TQM practice, as a part of organizational culture, shapes the TQM-oriented organization culture and promotes organization to change, and then all organization members change. Based on these analyses, the next hypothesis is proposed:

Hypothesis 2 (H2): Total quality control (TQM) positively impacts on executive ability (EA).

In addition, empirical studies have shown significant positive relationship between authority/communication and working efficiency. Researchers also defend that it is top management duty to lead the movement for quality. In this sense, leaders are expected to define organizational strategy and mission, values and principles that will inspire TQM oriented management practices. At the same time, through effective authority and communication to all members, the strategic activities obtain good working efficiency.

In organization level, Walter and Bruch's (2010) research manifested, transformational leadership behaviors created transformational leadership climates and the degree throughout the organization can direct TL behaviors toward their followers. In individual level, individualized consideration could be used to encourage people to continually improve job and quality skills. To this extent, leaders could visibly apply TQM principles to their own behavior, for example, by dedicating their own time toward learning. In line with above literature review, the third hypothesis should be inferred.

Hypothesis 3 (H3): Executive ability (EA) positively impacts on sustainable competitive advantage (SCA).

Executive functions are adaptive, goal-directed behaviors that enable individuals to override more automatic or established thoughts and responses and executive ability is the core of them. Total quality management (TQM) adoption success is a changing process (Yusof \& Aspinwall, 2000). The previous study came to a conclusion that total quality management (TQM) requires a special type of leadership executive activity in order to obtain human performance through creativity, problem-solving, teamwork, value adding contributions and a dedication and commitment to continuous improvement (Zairi, 1994). The European Centre for Business Excellence identifies the "top 3 things affecting quality": culture, continuous improvement, supply chain management. The author emphasized that perhaps, the most interesting initial findings are to do with 
Quality Leaders required for the 21st century (Oakland, 2010). So the forth hypothesis is proposed.

Hypothesis 4 (H4): Executive ability (EA) mediates the relationship between total quality management (TQM) and sustainable competitive advantage (SCA).

Figure 1 presents the conceptual framework of the research and depicts the main research stream of this study.

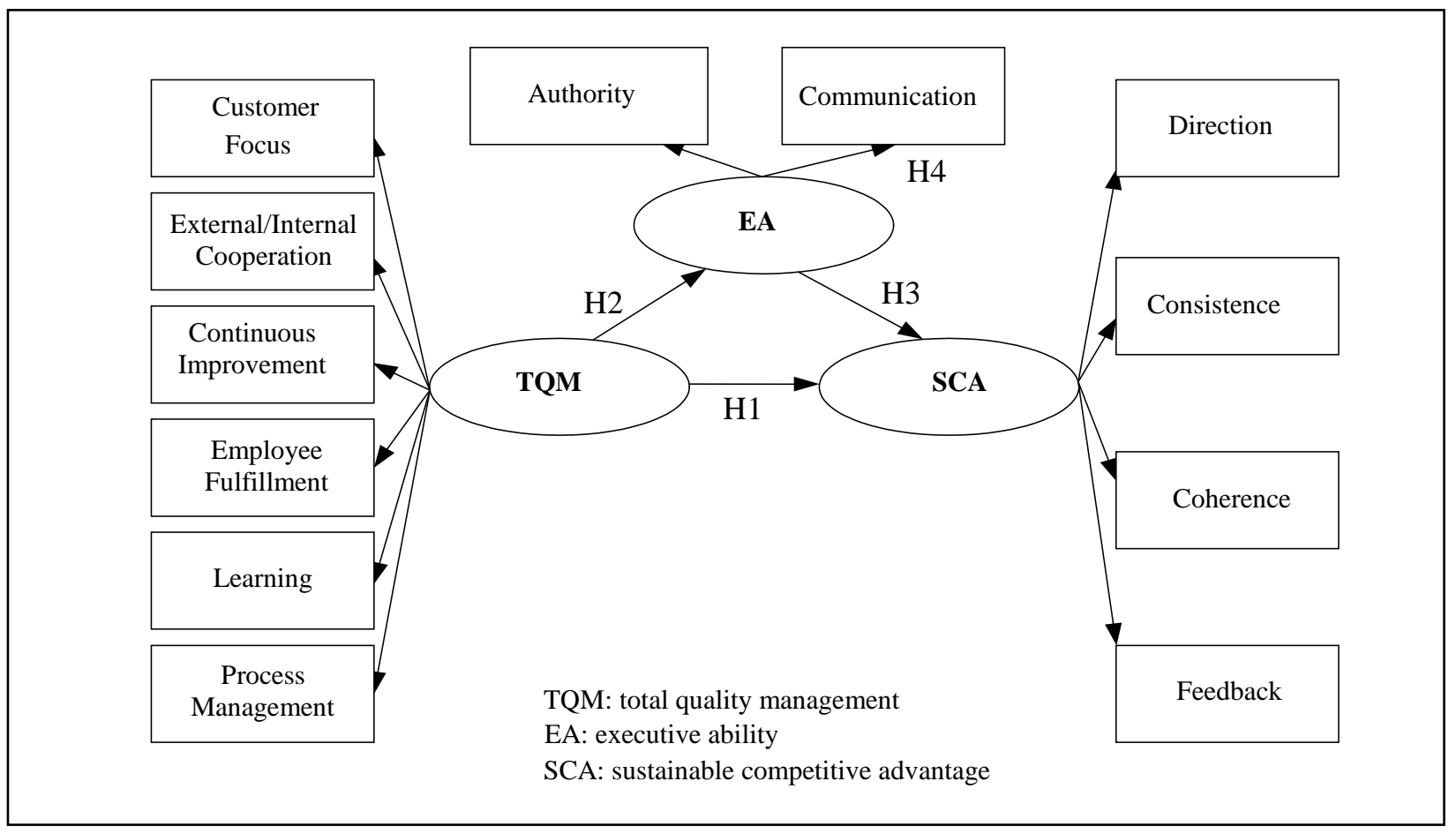

Figure 1. Conceptual framework of research.

\section{Methodology}

\section{Questionnaire Development and Pilot Test}

Testing the above hypotheses requires data on total quality management, executive ability, and sustainable competitive advantage. The main method utilized in this paper was a survey research using multiple items. In order to get needed data, three questionnaires were selected and adopted rooter in Wang et al. (2012), Neilson et al. (2008), and Doeleman et al. (2012). Table 1 lists the constructs, definitions, and sources of scales.

The questionnaire was first in English edition. Since the survey was conducted in Chinese, managers in practice and academics were invited to deal with the translation. In order to keep up with the pace of questionnaire between two editions, method of forward-translation and back-translation were adopted. In addition, the terminology and interpretation of items were all disposed to the extent to Chinese context and respondents' knowledge required to respond appropriately and at last the final draft of questionnaire was finished.

Soon afterwards, respondent anonymity, meaning anonymity of the items measurement, and pilot-tested by 100 employee at all levels were operated to view possible defects and doubts. Result of the pilot-test appeared that all variables had reliability exceeding the standard value 0.7 suggested by Hair et al., and one item that did not significantly contribute to the reliability was eliminated. 
In the end, formal questionnaire completed, and of which, total quality management has six dimensions with 21 items; executive ability has two dimensions with five items and sustainable competitive advantage has four dimensions with 11 items. The questionnaire all included 37 items that are retained for the present research. Items were measured on a seven-point Likert-type scale ranging from strongly disagree to strongly agree.

Table 1

Construct Definitions and Sources

\begin{tabular}{lll}
\hline Construct & Construct definition & Construct source \\
\hline Total quality management & $\begin{array}{l}\text { The organization adopts customer focus, internal/external } \\
\text { cooperation, continuous improvement, employee fulfillment, } \\
\text { learning and process management. }\end{array}$ & Wang et al. (2012) \\
\hline $\begin{array}{l}\text { Executive ability } \\
\begin{array}{l}\text { Sustainable competitive } \\
\text { advantage }\end{array}\end{array}$ & $\begin{array}{l}\text { Degree that employees have been authorized and given enough } \\
\text { communication in all aspects. }\end{array}$ & Neilson et al. (2008) \\
\hline
\end{tabular}

\section{Sample and Data Collection}

The samples used in this study are collected from Southern Taiwan Science Park in Tainan city. The questionnaire was sent to Tainan Technology Industrial Park Service Center and at the same time sampling plan was provided. Personalized cover letters and a pre-paid envelope accompanying questionnaire assured confidentiality of the responses. Furthermore, to encourage high participation, respondents were offered an executive summary of the study findings on completion of the study. The effective sample size was 252 and the overall effective response rate was $84 \%$ (252/300). The sample size of 252 was adequate for models with three constructs recommendations of Hair et al.

\section{Results and Analyses}

\section{Reliability and Validity Analyses}

Two-Step Structural Equation Model (SEM) was employed for model testing. Maximum likelihood was used for all parameter estimation with Amos software. First confirmatory factor analysis (CFA) is conducted to evaluate the model used to measure the modeled constructs. CFA enables testing of the reliability, convergent validity, and discriminate validity of the measurement model. The reliability and internal validity of the measurement model is examined by calculating the composite reliability (CR) and average variance extracted (AVE).

Table 2 shows that all the constructs have acceptable composite reliability coefficients, since they exceed 0.6 (Hair et al., 1998). The AVE of each measure accounts for more than $50 \%$ of the variance, as suggested by Bagozzi and Yi (1988), and indicates that the variance captured by the construct exceeds that due to the measurement error (Fornell \& Larcker, 1981). Therefore, the measurement model has adequate internal validity.

Convergent validity measures the correlation between two observed variables used to measure the same construct and is expected when the estimated pattern coefficient on the underlying construct factor of the estimated pattern of each coefficient is significant. Items have factor loadings exceeding 0.45 . Table 2 lists the convergent validity result of each latent variable. The standardized factor loadings of each sub-dimension all exceed 0.45 and are significant. Convergent validity thus was achieved for all the study constructs. 
Discriminate validity was assessed using the approach suggested by Fornell and Larcker (1981). Examining the AVE for each of the latent constructs and comparing this with the squared correlations among the constructs revealed that the shared variance among any two constructs (that is, the square of their inter-correlation) was always less than the average variance explained by the construct, suggesting discriminate validity. Table 3 lists the result of discriminate validity. This study concludes that all measures exhibit construct validity. Based on all of the reliability and validity analysis, the construct scale appears to exhibit satisfactory measurement qualities and is adequate.

Table 2

Construct Reliability and Convergent Validity Coefficient

\begin{tabular}{lllllll}
\hline Construct & $\begin{array}{l}\text { Number of } \\
\text { items }\end{array}$ & $\begin{array}{l}\mathrm{SFL}^{\mathrm{a}} \\
(\min -\mathrm{max})\end{array}$ & $\begin{array}{l}\text { T-Value } \\
(\min -\max )\end{array}$ & $\alpha^{\mathrm{a}}$ & $\mathrm{CR}^{\mathrm{a}}$ & $\mathrm{AVE}^{\mathrm{a}}$ \\
\hline Total quality management (2nd order CFA) & 6 & $0.72-0.93$ & $13.05-19.55$ & 0.95 & 0.95 & 0.74 \\
Customer focus (TQM1) & 3 & $0.82-0.88$ & $17.04-22.22$ & 0.88 & 0.88 & 0.72 \\
Internal/external cooperation (TQM2) & 2 & $0.81-0.85$ & $9.93-24.37$ & 0.87 & 0.82 & 0.69 \\
Continuous improvement (TQM3) & 3 & $0.81-0.87$ & $11.69-18.50$ & 0.88 & 0.88 & 0.77 \\
Employee fulfillment (TQM4) & 3 & $0.76-0.82$ & $13.72-15.84$ & 0.84 & 0.85 & 0.65 \\
Learning (TQM5) & 4 & $0.85-0.87$ & $13.90-15.87$ & 0.92 & 0.92 & 0.74 \\
Process management (TQM6) & 6 & $0.79-0.88$ & $10.52-22.37$ & 0.92 & 0.91 & 0.68 \\
Executive ability (2nd order CFA) & 2 & $0.92-0.93$ & $12.33-12.39$ & 0.93 & 0.92 & 0.86 \\
Authority (EA1) & 2 & $0.87-0.91$ & $13.67-15.08$ & 0.88 & 0.88 & 0.79 \\
Communication (EA2) & 3 & $0.85-0.91$ & $14.05-14.45$ & 0.90 & 0.90 & 0.81 \\
Sustainable competitive advantage (2nd order CFA) & 4 & $0.91-0.94$ & $9.29-9.41$ & 0.96 & 0.96 & 0.85 \\
Direction (SCA1) & 2 & $0.89-0.91$ & $14.05-14.45$ & 0.90 & 0.90 & 0.81 \\
Consistency (SCA2) & 2 & $0.90-0.91$ & $14.88-17.01$ & 0.90 & 0.90 & 0.82 \\
Coherence (SCA3) & 4 & $0.83-0.90$ & $14.08-16.36$ & 0.92 & 0.94 & 0.80 \\
Feedback (SCA4) & 3 & $0.88-0.92$ & $12.54-18.48$ & 0.92 & 0.93 & 0.80 \\
\hline
\end{tabular}

Notes. a SFL: standardized factor loading; $\alpha$ : Cronbach's $\alpha$ coefficient; CR: composite reliability; AVE: average variance extracted.

Table 3

Discriminate Validity Coefficient ${ }^{a}$

\begin{tabular}{lllllllllllll}
\hline & $\underline{\text { TQM1 }}$ & $\underline{\text { TQM2 }}$ & $\underline{\text { TQM3 }}$ & $\underline{\text { TQM4 }}$ & $\underline{\text { TQM5 }}$ & $\underline{\text { TQM6 }}$ & $\underline{\text { EA1 }}$ & $\underline{\text { EA2 }}$ & $\underline{\text { SCA1 }}$ & $\underline{\text { SCA2 }}$ & $\underline{\text { SCA3 }}$ & $\underline{\text { SCA4 }}$ \\
\hline TQM1 & 0.85 & & & & & & & & & & & \\
TQM2 & $0.69^{* *}$ & 0.83 & & & & & & & & & & \\
TQM3 & $0.64^{* *}$ & $0.78^{* *}$ & 0.84 & & & & & & & & & \\
TQM4 & $0.62^{* *}$ & $0.74^{* *}$ & $0.81^{* *}$ & 0.80 & & & & & & & & \\
TQM5 & $0.62^{* *}$ & $0.79^{* *}$ & $0.83^{* *}$ & $0.85^{* *}$ & 0.86 & & & & & & & \\
TQM6 & $0.67^{* *}$ & $0.74^{* *}$ & $0.79^{* *}$ & $0.76^{* *}$ & $0.85^{* *}$ & 0.83 & & & & & & \\
EA1 & $0.66^{* *}$ & $0.71^{* *}$ & $0.72^{* *}$ & $0.70^{* *}$ & $0.76^{* *}$ & $0.76^{* *}$ & 0.89 & & & & & \\
EA2 & $0.63^{* *}$ & $0.77^{* *}$ & $0.75^{* *}$ & $0.72^{* *}$ & $0.79^{* *}$ & $0.77^{* *}$ & $0.85^{* *}$ & 0.88 & & & & \\
SCA1 & $0.58^{* *}$ & $0.69^{* *}$ & $0.73^{* *}$ & $0.70^{* *}$ & $0.77^{* *}$ & $0.76^{* *}$ & $0.78^{* *}$ & $0.79^{* *}$ & 0.90 & & & \\
SCA2 & $0.62^{* *}$ & $0.72^{* *}$ & $0.76^{* *}$ & $0.74^{* *}$ & $0.81^{* *}$ & $0.80^{* *}$ & $0.81^{* *}$ & $0.84^{* *}$ & $0.89^{* *}$ & 0.91 & & \\
SCA3 & $0.65^{* *}$ & $0.73^{* *}$ & $0.79^{* *}$ & $0.80^{* *}$ & $0.83^{* *}$ & $0.81^{* *}$ & $0.84^{* *}$ & $0.83^{* *}$ & $0.85^{* *}$ & $0.85^{* *}$ & 0.89 & \\
SCA4 & $0.58^{* *}$ & $0.70^{* * *}$ & $0.76^{* *}$ & $0.78^{* *}$ & $0.79^{* *}$ & $0.72^{* *}$ & $0.80^{* *}$ & $0.81^{* *}$ & $0.82^{* *}$ & $0.83^{* *}$ & $0.87^{* *}$ & 0.90 \\
\hline
\end{tabular}

Notes. a: Diagonal elements (bold) are the square root of average variance extracted (AVE) between the constructs and their measures. Off-diagonal elements are correlations between constructs. 


\section{Structural Model and Hypotheses Testing}

Structural model testing. The simultaneous maximum-likelihood-estimation procedures are used to examine the hypothesized relationships among total quality management, executive ability, and sustainable competitive advantage. Figure 2 and Table 4 show that the structural model exhibits a good fit with the data, with fit indices of Root Mean Square Error of Approximation (RMSEA), Goodness-of-Fit Index (GFI), Adjusted Goodness-of-Fit Index (AGFI), and Comparative Fit Index (CFI) fulfilling the respective benchmarks (Bagozzi \& Yi, 1988; Hair et al., 1998).

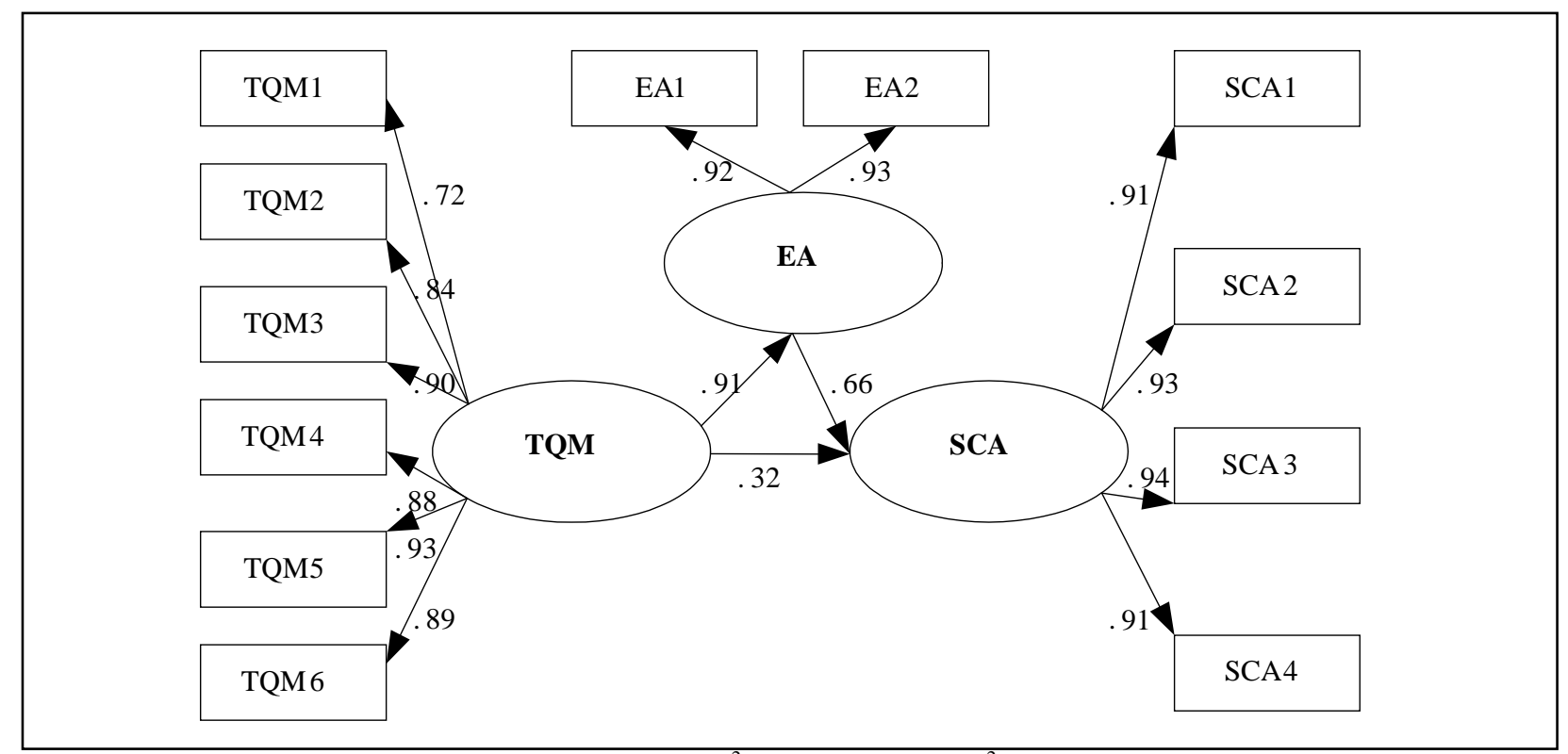

Figure 2. Path diagram of the research model. Note: $\chi^{2}=166.27, \mathrm{df}=51, \chi^{2} / \mathrm{df}=3.26 ; \mathrm{GFI}=0.90, \mathrm{AGFI}=0.85$, CFI $=0.970, \mathrm{RMR}=0.023 \mathrm{RFI}=0.939 \mathrm{IFI}=0.970 \mathrm{PGFI}=0.583$.

Table 4

Testing Indicators of Model

\begin{tabular}{|c|c|c|c|c|}
\hline Test statistics & & Standard value & Test result & Model fit $(\mathrm{Y} / \mathrm{N})$ \\
\hline \multirow{6}{*}{ Absolute fitness index } & $\chi^{2}$ & $\mathrm{P} \geqq \alpha$ value & 166.27 & $\mathrm{~N}$ \\
\hline & $\chi^{2} / \mathrm{df}$ & $1-5$ & 3.26 & $\mathrm{Y}$ \\
\hline & GFI & $>0.9$ & 0.90 & $\mathrm{Y}$ \\
\hline & PGFI & $>0.5$ & 0.59 & $\mathrm{Y}$ \\
\hline & RMR & $<0.08$ & 0.022 & $\mathrm{Y}$ \\
\hline & RMSEA & $<0.08$ & $0.095<0.1$ & $\mathrm{Y}$ \\
\hline \multirow{4}{*}{ Baseline comparison } & NFI & $>0.9$ & 0.96 & $\mathrm{Y}$ \\
\hline & CFI & $>0.9$ & 0.97 & $\mathrm{Y}$ \\
\hline & RFI & $>0.9$ & 0.94 & $\mathrm{Y}$ \\
\hline & IFI & $>0.9$ & 0.97 & $\mathrm{Y}$ \\
\hline \multirow{2}{*}{$\begin{array}{l}\text { Parsimony-adjusted } \\
\text { measures }\end{array}$} & PNFI & $>0.5$ & 0.74 & $\mathrm{Y}$ \\
\hline & PCFI & $>0.5$ & 0.75 & $\mathrm{Y}$ \\
\hline
\end{tabular}

Hypotheses testing. Figure 2 and Table 5 show the path coefficients for the model and their significance. Regarding the hypothesis tests, all of the hypothesized relationships are supported for the estimated structural model. 
Total quality management significantly and positively affects both sustainable competitive advantage (path coefficient TQM to SCA = 0.32) and executive ability (path coefficient TQM to EF $=0.91$ ). Furthermore, executive ability also significantly and positively affects sustainable competitive advantage (path coefficient EF to $\mathrm{SCA}=0.66$ ). Therefore, $\mathrm{H} 1, \mathrm{H} 2$, and $\mathrm{H} 3$ are supported.

Table 5

Path Coefficient Testing

\begin{tabular}{lllll}
\hline No. $\mathrm{H}$ & Path & Hypothesis relationship & Path value & Support (Y/N) \\
\hline H1 & TQM $\rightarrow$ SCA & Positive & 0.32 & Supported \\
H2 & TQM $\rightarrow$ EA & Positive & 0.91 & Supported \\
H3 & EA $\rightarrow$ SCA & Positive & 0.66 & Supported \\
\hline
\end{tabular}

\section{Mediating Effect of Executive Factor}

For the mediation analyses, the indirect effects are estimated using the method of Amos based on Sobel. The method provided an approximate significance test for the indirect effect of the independent variable on the dependent variable via the mediator. Figure 3 shows the testing formula. As z $>2$, the indirect effect is significant. The analytical results show that $\mathrm{a} * \mathrm{~b}=0.91 * 0.66=0.60$; $\mathrm{z}$-value of indirect effect in Sobel-testing is equal to $4.6>1.96$, and so, the indirect effect is positively significant. That is to say, executive ability mediates the influence of TQM on organization's sustainable competitive advantage. Hypothesis 4 thus is supported.

Furthermore, the ratio of indirect effect to total effect is $65.2 \%[0.60 /(0.32+0.60)]$, and so the mediating effect is partial mediation.

$$
\mathrm{Z}=\frac{a \times b}{s e(a b)}=\frac{a \times b}{\sqrt{a^{2}(\operatorname{se}(b))^{2}+b^{2}(\operatorname{se}(a))^{2}}}
$$

Note:

1. The path from TQM to transformational leadership is denoted as a and its standard error is se (a).

2. The path from transformational leadership to sustainable competitive advantage is denoted as $b$ and its standard error is se (b).

3. Se $(a b)$ is standard error of mediator.

Figure 3 Sobel test formula. Note: 1. The path from TQM to TL denoted as a and its standard error is se (a). 2. The path from TL to SCA is denoted as b and its standard error is se (b). 3. Se (ab) is standard error of mediator.

Table 6

Mediating Effect (Indirect Effect)

\begin{tabular}{llllll}
\hline Latent invariable & Latent variable & Direct effect & Indirect effect & Total effect & Hypotheses (Y/N) \\
\hline \multirow{2}{*}{ SCA } & TQM & 0.32 & $0.60(0.91 * 0.66)$ & 0.92 & $\mathrm{H}_{1}$ Supported \\
EA & EA & 0.66 & & 0.66 & $\mathrm{H}_{3}$ Supported \\
\hline
\end{tabular}

\section{Discussion, Conclusions, Implications, and Limitations}

\section{Discussion and Conclusions}

The present study investigated the relations among total quality management, executive ability, and organizational sustainable competitive advantage. The results indicate that TQM-linked activity should 
positively impact organizational sustainable competitive advantage when executive ability is taken in practice. Based on literature review, this study proposes and hypothesizes H1-H4 and the analytical results support all of the proposed hypotheses. Specially, empirical discussions of the test results and the conclusions state that:

First, total quality management positively affects organizational sustainable competitive advantage (Sureshchandar et al., 2001; Wang et al., 2012). This study confirms that TQM positively affects organizational sustainable competitive advantage in manufacturers of Tainan industrial park. The inner mechanics may be that, TQM-link factor such as internal/external cooperation which improves organizational business environment, reduces the complexity of business context; or employee fulfillment and learning which is as a critical role of building a link between an organization's quality management strategy and its ability to create and maintain an advantage.

Second, this study found that TQM has positive effect to executive ability (direct effect coefficient/path coefficient is 0.91). These analytical results are consistent with those obtained by Puffer and McCarthy who stress that in a TQM context top management's ability to create a vision and promote change is at the heart of successful TQM implementation.

The third, executive ability fosters organization's sustainable competitive advantage and mediates the TQM \& organization's sustainable competitive advantage (indirect effect coefficient is 0.60 ). This result means that when organization has adopted TQM as a strategy for the group, increase of executive ability can be obtained. That is to say, TQM strengthens the executive ability and executive ability promotes TQM implementation. And then, when TQM strategy and executive ability integrate, employees will be stronger to be incentive, more proactive participation emerge; organization has a clear goal, and practical execution has been gotten. Finally, due to the emphasis on continuous improvement, the quality of management activities will be improved in next circle. As a result, the organization is optimal and obtains excellence moving in circle.

\section{Managerial Practice Implications}

First, TQM positively affects organization's sustainable competitive advantage. TQM-adopting organization achieves sustainable competitive advantage in customer focus, internal/external cooperation, continuous improvement, employee fulfillment, learning, and process management. It also shows that manufacturers of Tainan industrial park identify the areas of TQM in which they invest and the areas requiring improvements. However, the degree of implementation of the basic elements of TQM influences business performance. In this study, elements of TQM such as continuous improvement (factor loading is 0.90), learning (factor loading is 0.93), and process management (factor loading is 0.89) are most important for firm's TQM practice. Manufacturers must effectively reinforce these elements in ways such as creating a strong learning atmosphere, providing enough incentive and opportunity to learn, and strengthening the system management and innovation.

Second, executive ability fosters firm sustainable competitive advantage. Manufacturers of Tainan industrial park are aware that executive ability is fundamental to organization excellence. Manufacturers must shape positive values, advocate optimism and enthusiasm, and strengthen the work vision, mission, and confidence.

Third, TQM identifiably affects executive ability. Total quality management (TQM) is widely considered as a management philosophy, and means to transform the traditional managerial style including leadership style. So firm leader must be in pursuit of changing proactively, and keep balance in initiating and consideration. 
Fourth, executive ability mediates the TQM and organization sustainable competitive advantage. Just as former analysis, correct strategy is the first step and then how to make strategy in reality is more essential and only strong executive ability can make strategy become possible. Organization must pay great attention to authority and communication in order to gather all staffs strength to the core task. That is to say, executive ability is the hinge of practice; two elements of TQM-linked activity and strong executive ability integrated can provide explicit direction, consistence in all time, coherence at all parts and unblocked communicate channel, all members in one heart and then lead to organization excellence (indirect effect is 0.60 and ratio of indirect effect to total effect is $65.2 \%$ ).

\section{Research Limitations and Future Research Directions}

Firstly the questionnaire in this study was translated form English-edition but used in Chinese context. Although the contents of questionnaire was modified based on the understanding habit of Chinese people, the main structure was kept pace with the original edition. Future study may firstly create scales based on the Chinese culture.

Secondly the data were collected in one scientific industrial park in Tainan, which limits the generalizability of the results. Future study may enlarge the zones, occupations, and nations and strengthen the generalizability of conclusions drawn from this study.

Thirdly this study was based on cross-sectional data. Does TQM or executive ability positively affect long term organizational sustainable competitive advantage? A major gap exists in the related literature on longitudinal studies. This study suggests that subsequent researchers perform longitudinal studies based on long-term observations or interviews regarding actual implementation to provide further insights regarding probable causations.

\section{References}

Ashkanasy, N. M., Härtel, C. E., \& Zerbe, W. J. (Eds.). (2000). Emotions in the workplace: Research, theory, and practice. Westport, CT, US: Quorum Books/Greenwood Publishing Group.

Avolio, B. J., Zhu, W., Koh, W., \& Bhatia, P. (2004). Transformational leadership and organizational commitment: Mediating role of psychological empowerment and moderating role of structural distance. Journal of Organizational Behavior, 25(8), 951-968.

Barney, J. (1991). Firm resources and sustained competitive advantage. Journal of Management, 17(1), 99-120.

Benson, D. (2015). The five fundamental tasks of a transformational leader. Physician Leadership Journal, 2(5), 58-63.

Chatfield, A., Najem Shlemoon, V., Redublado, W., \& Darbyshire, G. (2014). Creating value through virtual teams: A current literature review. Australasian Journal of Information Systems, 18(3), 257-269.

Chatterjee, S., Chatterjee, S., Narayanan, V., Narayanan, V., Malek, W., \& Malek, W. (2016). How strategy execution maps guided cisco system's sales incentive compensation plan. Strategy \& Leadership, 44(6), 25-34.

Chong, A. Y. L., Ooi, K. B., Lin, B., \& Teh, P. L. (2010). TQM, knowledge management and collaborative commerce adoption: A literature review and research framework. Total Quality Management, 21(5), 457-473.

Das, A., Kumar, V., \& Kumar, U. (2011). The role of leadership competencies for implementing TQM: An empirical study in Thai manufacturing industry. International Journal of Quality \& Reliability Management, 28(2), 195-219.

Deinert, A., Homan, A. C., Boer, D., Voelpel, S. C., \& Gutermann, D. (2015). Transformational leadership sub-dimensions and their link to leaders' personality and performance. The Leadership Quarterly, 26(6), 1095-1120.

Dóci, E., \& Hofmans, J. (2015). Task complexity and transformational leadership: The mediating role of leaders' state core self-evaluations. The Leadership Quarterly, 26(3), 436-447.

Doeleman, H. J., ten Have, S., \& Ahaus, K. (2012). The moderating role of leadership in the relationship between management control and business excellence. Total Quality Management \& Business Excellence, 23(5-6), 591-611. 
Ewen, C., Wihler, A., Blickle, G., Oerder, K., Ellen, B. P., Douglas, C., \& Ferris, G. R. (2013). Further specification of the leader political skill-leadership effectiveness relationships: Transformational and transactional leader behavior as mediators. The Leadership Quarterly, 24(4), 516-533.

Fornell, C., \& Larcker, D. F. (1981). Evaluating structural equation models with unobservable variables and measurement error. Journal of Marketing Research, 18(1), 39. doi:10.2307/3151312

Kanji, G. K., \& Wallace, W. (2000). Business excellence through customer satisfaction. Total Quality Management, 11, 979-998.

Khanam, S., Siddiqui, J., \& Talib, F. (2013). Role of information technology in total quality management: A literature review. International Journal of Advanced Research in Computer Engineering and Technology, 2(8), 2433-2445.

Kluse, C. (2009). TQM and the government: The importance of leadership and personal transformation. The Journal for Quality and Participation, 32(3), 27.

Menges, J. I., Walter, F., Vogel, B., \& Bruch, H. (2011). Transformational leadership climate: Performance linkages, mechanisms, and boundary conditions at the organizational level. The Leadership Quarterly, 22(5), 893-909.

Neilson, G. L., Martin, K. L., \& Powers, E. (2008). The secrets to successful strategy execution. Harvard Business Review, 86(6), 2 .

Oakland, J. (2011). Leadership and policy deployment: The backbone of TQM. Total Quality Management \& Business Excellence, 22(5), 517-534.

Osseo-Asare, A. E., Longbottom, D., \& Chourides, P. (2007). Managerial leadership for total quality improvement in UK higher education. The TQM Magazine, 19(6), 541-560.

Schenkel, M., Caniëls, M. C., Krikke, H., \& van der Laan, E. (2015). Understanding value creation in closed loop supply chains - past findings and future directions. Journal of Manufacturing Systems, 37, 729-745.

Sureshchandar, G. S., Rajendran, C., \& Kamalanabhan, T. J. (2001). Customer perceptions of service quality: A critique. Total Quality Management, 12, 111-124.

Ten Have, S., ten Have, W., Stevens, F., vander Elst, M., \& Pol-Coyne, F. (2003). Key management models: The management tools and practices that will improve your business. London: Pearson Education.

Ugboro, I. O., \& Obeng, K. (2000). Top management leadership, employee empowerment, job satisfaction, and customer satisfaction in TQM organizations: An empirical study. Journal of Quality Management, 5(2), 247-272.

Wade, M, \& Hulland, J. (2004). The resource-based view and information systems research: Review, extension, and suggestions for future research. MIS Quarterly, 28(1), 107-142.

Waldman, D. A. (1993). A theoretical consideration of leadership and total quality management. The Leadership Quarterly, 4(1), 65-79.

Walter, F., \& Bruch, H. (2010). Structural impacts on the occurrence and effectiveness of transformational leadership: An empirical study at the organizational level of analysis. The Leadership Quarterly, 21(5), 765-782.

Wang, C. H., Chen, K. Y., \& Chen, S. C. (2012). Total quality management, market orientation and hotel performance: The moderating effects of external environmental factors. International Journal of Hospitality Management, 31(1), 119-129.

Wong, C. Y., \& Karia, N. (2010). Explaining the competitive advantage of logistics service providers: A resource-based view approach. International Journal of Production Economics, 128(1), 51-67.

Yusof, S. R. M., \& Aspinwall, E. (2000). Total quality management implementation frameworks: comparison and review. Total Quality Management, 11(3), 281-294.

Zairi, M. (1994). Leadership in TQM implementation: Some case examples. The TQM Magazine, 6(6), 9-16.

Zhang, Z., Wang, M. O., \& Shi, J. (2012). Leader-follower congruence in proactive personality and work outcomes: The mediating role of leader-member exchange. Academy of Management Journal, 55(1), 111-130. 